NASA/CR-2005-213852

\title{
Evaluation and Validation of the Messinger Freezing Fraction
}

David N. Anderson and Jen-Ching Tsao

Ohio Aerospace Institute, Brook Park, Ohio 
Since its founding, NASA has been dedicated to the advancement of aeronautics and space science. The NASA Scientific and Technical Information (STI) Program Office plays a key part in helping NASA maintain this important role.

The NASA STI Program Office is operated by Langley Research Center, the Lead Center for NASA's scientific and technical information. The NASA STI Program Office provides access to the NASA STI Database, the largest collection of aeronautical and space science STI in the world. The Program Office is also NASA's institutional mechanism for disseminating the results of its research and development activities. These results are published by NASA in the NASA STI Report Series, which includes the following report types:

- $\quad$ TECHNICAL PUBLICATION. Reports of completed research or a major significant phase of research that present the results of NASA programs and include extensive data or theoretical analysis. Includes compilations of significant scientific and technical data and information deemed to be of continuing reference value. NASA's counterpart of peerreviewed formal professional papers but has less stringent limitations on manuscript length and extent of graphic presentations.

- TECHNICAL MEMORANDUM. Scientific and technical findings that are preliminary or of specialized interest, e.g., quick release reports, working papers, and bibliographies that contain minimal annotation. Does not contain extensive analysis.

- CONTRACTOR REPORT. Scientific and technical findings by NASA-sponsored contractors and grantees.
- CONFERENCE PUBLICATION. Collected papers from scientific and technical conferences, symposia, seminars, or other meetings sponsored or cosponsored by NASA.

- SPECIAL PUBLICATION. Scientific, technical, or historical information from NASA programs, projects, and missions, often concerned with subjects having substantial public interest.

- TECHNICAL TRANSLATION. Englishlanguage translations of foreign scientific and technical material pertinent to NASA's mission.

Specialized services that complement the STI Program Office's diverse offerings include creating custom thesauri, building customized databases, organizing and publishing research results ... even providing videos.

For more information about the NASA STI Program Office, see the following:

- Access the NASA STI Program Home Page at http://www.sti.nasa.gov

- E-mail your question via the Internet to help@sti.nasa.gov

- Fax your question to the NASA Access Help Desk at 301-621-0134

- Telephone the NASA Access Help Desk at 301-621-0390

- Write to:

NASA Access Help Desk

NASA Center for AeroSpace Information 7121 Standard Drive

Hanover, MD 21076 
NASA/CR-2005-213852

AIAA-2003-1218

\section{Evaluation and Validation of the Messinger Freezing Fraction}

David N. Anderson and Jen-Ching Tsao

Ohio Aerospace Institute, Brook Park, Ohio

Prepared for the

41st Aerospace Sciences Meeting and Exhibit

sponsored by the American Institute of Aeronautics and Astronautics

Reno, Nevada, January 6-9, 2003

Prepared under Cooperative Agreement NCC3-884

National Aeronautics and

Space Administration

Glenn Research Center 


\section{Acknowledgments}

This work was supported under a grant from NASA to the Ohio Aerospace Institute. The authors wish to thank Jim Riley of the FAA and Tom Bond of NASA for their support of this study and the IRT personnel for their continued commitment to excellent technical support.

This report contains preliminary

findings, subject to revision as analysis proceeds.

Available from

NASA Center for Aerospace Information 7121 Standard Drive

Hanover, MD 21076
National Technical Information Service 5285 Port Royal Road Springfield, VA 22100 


\title{
Evaluation and Validation of the Messinger Freezing Fraction
}

\author{
David N. Anderson and Jen-Ching Tsao \\ Ohio Aerospace Institute \\ Brook Park, Ohio 44142
}

\begin{abstract}
$\underline{\text { Abstract }}$
One of the most important non-dimensional parameters used in ice-accretion modeling and scaling studies is the freezing fraction defined by the heat-balance analysis of Messinger. For fifty years this parameter has been used to indicate how rapidly freezing takes place when super-cooled water strikes a solid body. The value ranges from 0 (no freezing) to 1 (water freezes immediately on impact), and the magnitude has been shown to play a major role in determining the physical appearance of the accreted ice. Because of its importance to ice shape, this parameter and the physics underlying the expressions used to calculate it have been questioned from time to time. Until now, there has been no strong evidence either validating or casting doubt on the current expressions.
\end{abstract}

This paper presents experimental measurements of the leading-edge thickness of a number of ice shapes for a variety of test conditions with nominal freezing fractions from 0.3 to 1.0 . From these thickness measurements, experimental freezing fractions were calculated and compared with values found from the Messinger analysis as applied by Ruff. Within the experimental uncertainty of measuring the leading-edge thickness, agreement of the experimental and analytical freezing fraction was very good. It is also shown that values of analytical freezing fraction were entirely consistent with observed ice shapes at and near rime conditions: At an analytical freezing fraction of unity, experimental ice shapes displayed the classic rime shape, while for conditions producing analytical freezing fractions slightly lower than unity, glaze features started to appear.

\section{Nomenclature}

$A_{c} \quad$ Accumulation parameter, dimensionless

$b \quad$ Relative heat factor, dimensionless

c Airfoil chord, cm $c_{p} \quad$ Specific heat of air, cal/g K

$c_{p, w s} \quad$ Specific heat of water at the surface temperature, cal $/ \mathrm{g} \mathrm{K}$

CL Tunnel centerline (mid-span) position

$d \quad$ Cylinder diameter or twice the leading-edge radius of airfoil, $\mathrm{cm}$

$D_{v} \quad$ Diffusivity of water vapor, $\mathrm{cm}^{2} / \mathrm{sec}$

$h_{c} \quad$ Convective heat-transfer coefficient, $\mathrm{cal} / \mathrm{s} \mathrm{m}^{2} \mathrm{~K}$

$h_{G} \quad$ Gas-phase mass-transfer coefficient, $\mathrm{g} / \mathrm{s} \mathrm{m}^{2}$

$k_{a} \quad$ Thermal conductivity of air, cal $/ \mathrm{s} \mathrm{m} \mathrm{K}$

$K \quad$ Inertia parameter, dimensionless

$K_{0} \quad$ Modified inertia parameter, dimensionless

$L W C \quad$ Cloud liquid-water content, $\mathrm{g} / \mathrm{m}^{3}$

MVD Water droplet median volume diameter, $\mu \mathrm{m}$

$n \quad$ Freezing fraction, dimensionless

$n_{a} \quad$ Freezing fraction calculated using Messinger analysis, dimensionless

$n_{e} \quad$ Freezing fraction from leading-edge ice thickness, dimensionless

$\mathrm{Nu} \quad$ Nusselt number, dimensionless

$p \quad$ Static pressure, $\mathrm{Nt} / \mathrm{m}^{2}$

$p_{w} \quad$ Vapor pressure of water in atmosphere, $\mathrm{Nt} / \mathrm{m}^{2}$

$p_{w w} \quad$ Vapor pressure of water at the icing surface, $\mathrm{Nt} / \mathrm{m}^{2}$

$r \quad$ Recovery factor, dimensionless

Re Reynolds number of model, dimensionless

$R e_{\delta} \quad$ Reynolds number of water droplet, dimensionless

Sc Schmidt number, dimensionless

SLD Super-cooled large droplet

$t_{f} \quad$ Freezing temperature of water, ${ }^{\circ} \mathrm{C}$

$t_{s} \quad$ Surface temperature, ${ }^{\circ} \mathrm{C}$

$t \quad$ Temperature, ${ }^{\circ} \mathrm{C}$

$T \quad$ Absolute temperature, $\mathrm{K}$

$V \quad$ Free-stream velocity of air, $\mathrm{m} / \mathrm{s}$

We Weber number based on droplet size and water properties, dimensionless

$W e_{c} \quad$ Weber number based on model size and air properties, dimensionless

$W e_{h} \quad$ Weber number based on water-film thickness and water properties, dimensionless 
$\beta_{0} \quad$ Collection efficiency at stagnation line, dimensionless

$\Delta \quad$ Ice thickness at stagnation line, $\mathrm{cm}$

$\phi \quad$ Water droplet energy transfer parameter, ${ }^{\circ} \mathrm{C}$

$\lambda \quad$ Water droplet range, $\mathrm{m}$

$\lambda_{\text {Stokes }} \quad$ Water droplet range if Stokes Law applies, $\mathrm{m}$

$\Lambda_{f} \quad$ Latent heat of freezing of water, cal $/ \mathrm{g}$

$\Lambda_{v} \quad$ Latent heat of evaporation of water, cal $/ \mathrm{g}$

$\mu \quad$ Viscosity of air, $\mathrm{g} / \mathrm{m} \mathrm{s}$

$\theta \quad$ Air energy transfer parameter, ${ }^{\circ} \mathrm{C}$

$\rho \quad$ Air density, $\mathrm{g} / \mathrm{m}^{3}$

$\rho_{i} \quad$ Ice density, $\mathrm{g} / \mathrm{m}^{3}$

$\rho_{w} \quad$ Liquid water density, $\mathrm{g} / \mathrm{m}^{3}$

$\tau \quad$ Accretion time, min

$\underline{\text { Subscripts }}$

st $\quad$ Static

tot Total

\section{Introduction}

One of the most important non-dimensional parameters used in ice-accretion modeling and scaling studies is the freezing fraction, $n$. Since Messinger ${ }^{1}$ introduced the term in his surface heat balance analysis fifty years ago, this parameter has been shown to have a strong effect on the shape of ice accretions. ${ }^{2,3}$ It is important that analytical expressions used to calculate it include all significant physical processes.

Messinger defined the freezing fraction as the fraction of water flux entering a control volume that freezes within the control volume. Along the stagnation line of a cylinder or airfoil water reaches the surface only by impingement. The portion that freezes is represented by the accumulated ice thickness. Thus, the nondimensional leading-edge ice thickness, $\Delta$, is:

$$
\frac{\Delta}{d}=n A_{c} \beta_{0}
$$

Here, $d$ is the cylinder diameter or twice the leadingedge radius for an airfoil. For the NACA 0012, the leading-edge radius is $0.0158 c$, where $c$ is the chord. $A_{c}$ is the accumulation parameter

$$
A_{c}=\frac{L W C V \tau}{d \rho_{i}}
$$

and $\beta_{0}$ is the collection efficiency of water droplets at the stagnation line. The Langmuir and Blodgett ${ }^{4}$ method for calculating $\beta_{0}$ will be presented below. In this paper we shall use $n_{e}$ to refer to freezing fractions calculated from experimental ice shapes using equation (1) and $n_{a}$ for analytical freezing fractions calculated from the equations given below.
For scaling studies, only the stagnation value of the freezing fraction is matched between scale and reference conditions. It is assumed that if a match is achieved there, the freezing fraction will match everywhere over the bodies of interest. The value of this stagnation freezing fraction as determined from analysis must be able to pass two tests. (i) It must lead to values consistent with the experimental ice thickness at the stagnation line (from eq. (1)), and (ii) it must also lead to values consistent with the ice shape at and near the leading edge. Test (ii) means that for an analytical freezing fraction of 1 , ice shapes must be rime, and if $n_{a}$ is calculated to be less than 1, ice shapes must show glaze features at the stagnation line. If either of the requirements (i) or (ii) is not met, the analysis must be deficient.

In 1988 Bilanin $^{5}$ analyzed Ruff ${ }^{2}$ ice tracings and calculated experimental freezing fractions using equation (1). Only for high freezing fractions did he find reasonable agreement between $n_{e}$ and the Messinger-analysis freezing fraction, $n_{a}$, and he concluded that at low $n$ the currently-used expression may not adequately account for water-film effects. However, the value of $n_{e}$ found by equation (1) is strongly dependent on the uncertainties inherent in recording and measuring small ice thicknesses and also somewhat affected by how accurately the $L W C$ is known for the icing tests. These potential problems were not addressed by Bilanin who worked with a limited data set.

This paper presents experimental measurements of the leading-edge thickness of a number of ice shapes recorded in the NASA Glenn Icing Research Tunnel (IRT) over a range of freezing fractions from 0.3 to 1.0. From the thickness measurements, $n_{e}$ was found from equation (1) and compared with the value of $n_{a}$ found using the method of Ruff, which was based on the Messinger surface heat-balance analysis.

\section{$\underline{\text { Analysis }}$}

\section{$\underline{\text { Stagnation Collection Efficiency }}$}

Each of the parameters of importance to this study, including freezing fraction, will be used in the form presented by Ruff ${ }^{2}$ and subsequently applied by Anderson ${ }^{3}$ in recent scaling studies.

The stagnation collection efficiency, $\beta_{0}$, in equation (1) was calculated from the expression given by Langmuir and Blodgett:

$$
\beta_{0}=\frac{1.40\left(K_{0}-1 / 8\right)^{.84}}{1+1.40\left(K_{0}-1 / 8\right)^{.84}}
$$

where the modified inertia parameter, $K_{0}$, is: 


$$
K_{0}=\frac{1}{8}+\frac{\lambda}{\lambda_{\text {Stokes }}}\left(K-\frac{1}{8}\right)
$$

Here $\lambda / \lambda_{\text {Stokes }}$ is the droplet range parameter, defined as the ratio of actual droplet range to that if Stokes drag law for solid-spheres applied. It is a function only of the droplet Reynolds number, $R e_{\delta}$ and was tabulated by Langmuir and Blodgett. The following fit to the Langmuir and Blodgett tabulation was used in this study:

$$
\frac{\lambda}{\lambda_{\text {Stokes }}}=\left(\begin{array}{l}
0.8388+0.001483 R e_{\delta} \\
+0.1847 \sqrt{R e_{\delta}}
\end{array}\right)^{-1}
$$

where the droplet Reynolds number is

$$
\operatorname{Re}_{\delta}=\frac{V M V D \rho_{w}}{\mu}
$$

The inertia parameter, $K$, in equation (4) is

$$
K=\frac{\rho_{w} M V D^{2} V}{18 d \mu}
$$

\section{Analytical Stagnation Freezing Fraction}

The freezing fraction, from Messinger's surface energy balance, can be written in the form,

$$
n_{a}=\frac{c_{p, w s}}{\Lambda_{f}}\left(\phi+\frac{\theta}{b}\right)
$$

This expression does not include heat lost from the surface due to water runback or to conduction into the model surface. The latter component of the heat balance is not likely to be important except when accretion first starts or soon after. The individual terms in this expression are $\phi$, the water energy transfer parameter; $\theta$, the air energy transfer parameter; and $b$, the relative heat factor, introduced by Tribus, et. al. ${ }^{6}$ These parameters are defined as

$$
\begin{gathered}
\phi=t_{f}-t_{s t}-\frac{V^{2}}{2 c_{p . w s}} \\
\theta=\left(t_{s}-t_{s t}-\frac{r V^{2}}{2 c_{p}}\right)+\frac{h_{G}}{h_{c}}\left(\frac{\frac{p_{w w}}{T_{s t}}-\frac{p_{t o t}}{T_{t o t}} \frac{p_{w}}{p_{s t}}}{\frac{1}{p_{t o t}}-\frac{p_{w w}}{T_{s t}}}\right) \Lambda_{v}(1) \\
b=\frac{L W C V \beta_{0} c_{p, w s}}{h_{c}}
\end{gathered}
$$

Equation (10) gives the form of $\theta$ employed by Ruff, which includes compressibility effects. Charpin and Fasso $^{7}$ and others have used a simpler form that ignores compressibility, but for icing conditions there is little difference in the values resulting from the two. Equation (10) was used in this study.

The second term in equation (10) accounts for evaporation. The gas-phase mass-transfer coefficient, $h_{G}$, can be found from

$$
h_{G}=\frac{h_{c}}{c_{p}}\left(\frac{P r}{S c}\right)^{0.67}
$$

where the Prandtl number is

$$
\operatorname{Pr}=\frac{c_{p} \mu}{k_{a}}
$$

and the Schmidt number is given by

$$
S c=\frac{\mu}{\rho D_{v}}
$$

The convective heat-transfer coefficient, $h_{c}$, was determined from the Nusselt number:

$$
h_{c}=\frac{k_{a}}{d} N u
$$

The evaluation for $N u$ at the stagnation line of a cylinder with laminar flow was reported by Kreith: ${ }^{8}$

$$
N u=1.14 \operatorname{Pr}^{0.4} \operatorname{Re}^{0.5}
$$

with

$$
\operatorname{Re}=\frac{V d \rho}{\mu}
$$

The air properties used in equation (16) should be based on the film temperature. For temperatures of interest to icing, $\operatorname{Pr}$ is effectively constant, and equation (16) can be simplified to

$$
N u=0.992 R e^{0.5}
$$

Poinsatte $^{9}$ measured heat-transfer coefficients at the stagnation line of an NACA 0012 airfoil in the IRT. Poinsatte defined his parameters using the chord as the length, but to be consistent with the practice in this study, they can be rewritten in terms of $d$, using $d=$ $0.0316 c$ for the NACA 0012 airfoil. Poinsatte's expression for $N u$ at $0^{\circ}$ angle of attack is then

$$
N u=1.10 R e^{0.472}
$$

and at $4^{\circ} \mathrm{AOA}$,

$$
N u=0.903 R e^{0.498}
$$

These correlations are remarkably close to the expression for cylinders in equation (18), supporting the approach used here of applying cylinder expressions to airfoils with the airfoil leading-edge radius substituted 
for cylinder radius. Equation (16) was used in the present study.

\section{$\underline{\text { IRT and Test Description }}$}

The icing test results used in this investigation were performed in the NASA Glenn IRT. The IRT is a closed-loop, refrigerated, sea level tunnel with a test section of 1.8 by $2.7 \mathrm{~m}$. The IRT has 10 spray bars. The cloud from these spray bars is calibrated periodically; for the tests reported here the calibration completed in the summer of $2000^{10}$ was used.

The models used for these tests were NACA 0012 61cm-span aluminum airfoil sections with chords of 80.0 , $53.3,35.6$ and $26.7 \mathrm{~cm}$. They were mounted vertically between splitter plates at the center of the IRT test section as shown typically in figure 1. Guide lines for locating ice-tracing templates were marked at the leading edge of each model at tunnel center, $\pm 2.5 \mathrm{~cm}$ and $\pm 5 \mathrm{~cm}$ from the center. All tests were run at $0^{\circ} \mathrm{AOA}$.

In preparing for a test, the temperature and airspeed in the test section and the air and water pressures on the spray manifolds were set. When these conditions stabilized at the set points, the spray nozzle valves were opened to initiate the spray. The IRT spray system reaches steady state in a few seconds, eliminating the need to shield the models during spray stabilization. At the completion of the spray duration, the nozzle valves closed and the tunnel fan was brought to a full stop. Personnel then entered the test section to record the ice shape through tracings and photographs.

For tracings, a heated ice knife cut from 0.16- to 0.32$\mathrm{cm}$-thick stainless-steel sheet was inserted into the leading edge of the ice to melt a thin horizontal slit down to the model surface. A cardboard template cut out to conform with the shape of the model near the leading edge was placed into this gap and a cross section of the ice shape traced onto the template with a pencil. Tracings were taken at two locations: the vertical center of the tunnel (91 cm from the floor) and at $2.5 \mathrm{~cm}$ above the center. The tracings were digitized and the $x-y$ coordinates for each ice shape recorded. The coordinates were normalized by the model chord when preparing presentation plots.

Ice shapes used in this study were obtained in scaling studies made in March 2001 and March and October 2002. Each of those test series included SLD and Appendix-C test conditions, and the 2001 scaling results have been reported previously. ${ }^{11,} 12$ To limit the analysis, only the Appendix-C subset of those tests was used for the present work. Three rime tests were eliminated from that subset because the recorded ice shapes had been obtained at conditions for which erosion had been seen in the past. What remained were forty sets of ice shapes at conditions producing a range of analytical freezing fractions from 0.28 to 1 .

The leading-edge ice thickness for each ice shape was determined by examining the $x-y$ coordinate data near the $y=0$ location. Because the tests were performed at $0^{\circ} \mathrm{AOA}$ and the origin of the coordinate system was at the leading edge of the clean model, the absolute value of $x$ at $y=0$ would ideally represent the ice thickness at the stagnation line. However, slight misalignments of the model with the flow sometimes displaced the actual stagnation line slightly above or below $y=0$. Therefore, the local minimum (for glaze ice) or maximum (for rime) absolute value of $x$ near $y=0$ was selected as the ice thickness. Ice shape differences between the two tracing locations typically did not appear to be significant, but differences in ice thickness at the leading edge were usually measurable.

\section{Uncertainty Analysis}

Tunnel and cloud conditions were recorded every 1, 3 or $5 \mathrm{sec}$ (depending on spray duration) over the length of the spray. Reported conditions are the time averages of these data histories. Estimates of the uncertainty in the reported average conditions were made by considering fluctuations of the values over time, possible instrument errors, uncertainties in tunnel calibration of $M V D$ and $L W C$ and differences in measurements from one location to another in the test section.

Total temperature was measured by 24 thermocouples

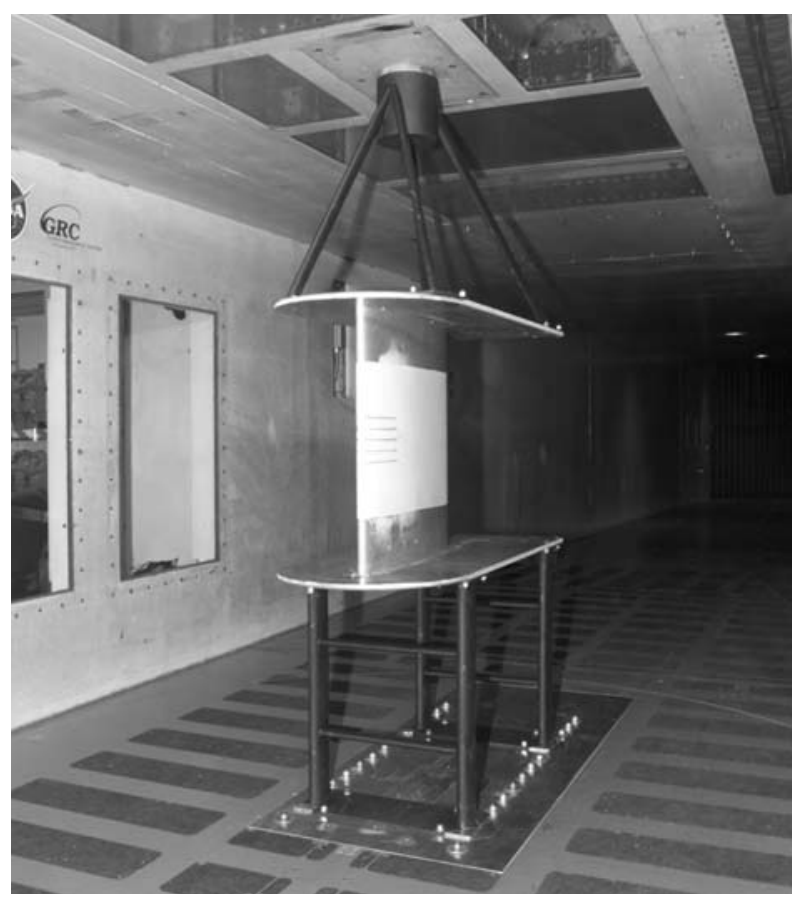

Figure 1. 61-cm-Span Model Installed in IRT Test Section. 
distributed over the turning vanes just upstream of the spray bars. These values were then averaged at each time interval to determine a temperature-time history. Including inherent uncertainty in the thermocouples themselves, it was estimated that the total uncertainty in temperature was on the order of $\pm 0.5^{\circ} \mathrm{C}$.

Test-section velocity was determined from the average total and average static pressures from 2 pitot-static probes, one located on the north wall and one on the south wall of the tunnel at the entrance to the test section. The maximum computed difference in velocities indicated by the two probes was $\pm 0.25 \%$. Pressures also fluctuated modestly with time such that the variation in velocity over the spray duration was less than $3 \%$.

The most significant contribution to $L W C$ uncertainty is the calibration process, and scatter in the calibration data suggests this uncertainty was about $\pm 12 \%$.

Most of the uncertainty in drop-size measurement came from interpreting results from the instruments used in calibration. The net uncertainty in MVD was estimated at $\pm 12 \%$. This uncertainty applies only to the particular instruments used (OAP and FSSP probes) in the IRT calibration and do not suggest a reference to an absolute value, which is unknown.

These estimated uncertainties in the test conditions produced approximate uncertainties of $\pm 2 \%$ in $\beta_{0}, \pm 12 \%$ in $A_{c}$ and $\pm 15 \%$ in $n$.

\section{$\underline{\text { Results and Discussion }}$}

\section{Leading-Edge Thickness}

The measured leading-edge thickness values, corresponding freezing fractions using equation (1) and the conditions for each test are listed in Table I in chronological order. Thickness values and $n_{e}$ for both midspan (CL) and $2.5 \mathrm{~cm}$ above mid-span $(\mathrm{CL}+2.5 \mathrm{~cm})$ are given. The absolute difference between the $\mathrm{CL}+2.5-\mathrm{cm}$ and the $\mathrm{CL}$ thickness for each test varied from 0 to $0.14 \mathrm{~cm}$. Also included in the table are the values of $\beta_{0}, A_{c}$ and $n_{a}$ computed using equations (2) to (17).

Sample ice tracings are reproduced in figure 2. The mid-span (CL) shape is shown with a shaded crosssection while the 2.5 -cm-above mid-span $(C L+2.5 \mathrm{~cm})$ is represented with a solid line. The spray conditions for figure 2 (a) produced a glaze accretion with an $n_{a}$ of 0.28 . While the tracings for the two locations looked very much alike, the leading-edge thicknesses for the two differed by $18.8 \%$. For low freezing fractions the features of the main ice shape tended to be somewhat random in nature; therefore, the leading-edge location and thickness were often difficult to define. Further- more, because the ice thickness was small for low freezing fractions, any inherent inaccuracies in the tracing process would have tended to produce larger percentage differences from tracing to tracing than would occur at higher freezing fractions. For the tests of Table I, when $n_{a}$ was less than 0.3 the $\mathrm{CL}+2.5$-cm thickness varied from -15.8 to $30.2 \%$ of the CL value. The highest relative difference occurred for a test using the smallest model, for which the inherent inaccuracies of manually tracing the ice were the greatest.

Figure 2 (b) gives the ice shapes recorded for a glaze accretion with a freezing fraction of 0.52 . The leadingedge features were better defined than for the shapes shown in figure 2 (a), and it was relatively easy to pick out the leading edge thickness from the ice-shape coordinates. Here the ice tracings for the two locations yielded thickness values that differed by $10.2 \%$.

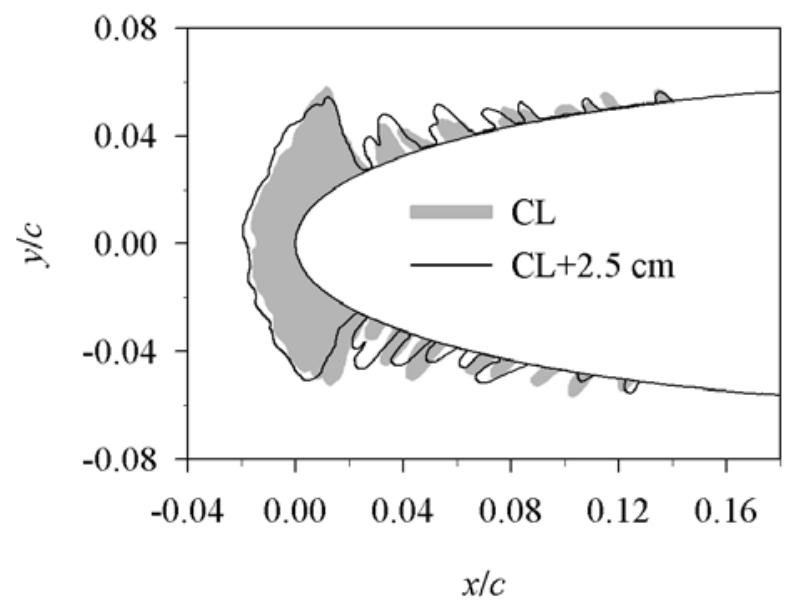

(a) Ice Shapes from 3-23-01 Run 2. Glaze Ice with $n_{a}$ $=0.28$.

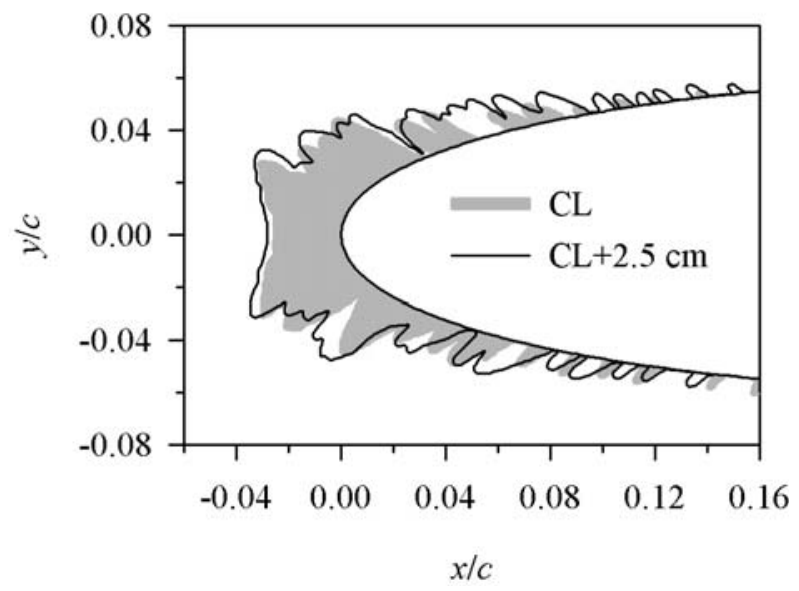

(b) Ice Shapes from 3-23-01 Run 7. Glaze Ice with $n_{a}$ $=0.52$.

Figure 2. Sample Ice Shapes. See Table I for Test Conditions. 
Table I.

Test Conditions, Leading Edge Thicknesses and Freezing Fractions

\begin{tabular}{|c|c|c|c|c|c|c|c|c|c|c|c|c|c|}
\hline \multirow[b]{2}{*}{ Date/Run } & \multirow[b]{2}{*}{$\begin{array}{c}c, \\
\mathrm{~cm}\end{array}$} & \multirow[b]{2}{*}{$\begin{array}{l}t_{s t}, \\
{ }^{\circ} \mathrm{C}\end{array}$} & \multirow[b]{2}{*}{$\begin{array}{c}V, \\
\mathrm{~m} / \mathrm{s}\end{array}$} & \multirow[b]{2}{*}{$\begin{array}{c}M V D, \\
\mu \mathrm{m}\end{array}$} & \multirow[b]{2}{*}{$\begin{array}{l}L W C, \\
\mathrm{~g} / \mathrm{m}^{3}\end{array}$} & \multirow[b]{2}{*}{$\underset{\min }{\tau,}$} & \multirow[b]{2}{*}{$\beta_{0}$} & \multirow[b]{2}{*}{$A_{c}$} & \multirow[b]{2}{*}{$n_{a}{ }^{*}$} & \multicolumn{2}{|c|}{$\Delta, \mathrm{cm}$} & \multicolumn{2}{|c|}{$n_{e}$} \\
\hline & & & & & & & & & & CL & $\begin{array}{c}\mathrm{CL}+ \\
2.5 \mathrm{~cm}\end{array}$ & CL & $\begin{array}{c}\mathrm{CL}+ \\
2.5 \mathrm{~cm}\end{array}$ \\
\hline $3-13-01 / 5$ & 80.0 & -7.1 & 57.5 & 45.9 & 0.915 & 13.8 & 0.827 & 1.879 & 0.292 & 1.21 & 1.26 & 0.308 & 0.322 \\
\hline $3-13-01 / 7$ & 0.0 & -7.0 & 48.5 & 3.2 & 979 & 4.5 & 0.801 & 1.780 & 0.310 & 1.17 & 14 & .325 & \\
\hline $3-14-01 / 5$ & 0.0 & -9.9 & 57.7 & 4.2 & 899 & 13.9 & 0.820 & 1.868 & 0.421 & 1.63 & .58 & 420 & \\
\hline $3-14-01 / 6$ & 80.0 & -9.8 & 47.6 & 41.4 & 958 & 14.9 & 0.789 & 1.757 & 0.453 & 1.5 & .58 & .433 & \\
\hline $3-14-$ & 80.0 & -12.6 & 58.1 & 43.4 & 0.889 & 14.0 & 0.817 & 1.871 & 0.541 & 1.84 & 1.98 & 0.477 & \\
\hline $3-15-$ & 80.0 & -14.9 & 57.8 & 43.2 & 0.891 & 14.0 & 0.816 & 1.865 & 0.637 & 2.32 & .26 & 0.604 & \\
\hline $3-15-$ & 80.0 & -18.7 & 57.9 & 43.6 & 885 & 14.1 & 0.817 & 1.872 & 0.791 & 2.87 & 04 & 0.741 & \\
\hline $3-19-01 / 5$ & 53.3 & -7.2 & 66.8 & 39.9 & & 7.3 & 0.857 & 1.885 & 0.284 & $0 .{ }^{2}$ & & 55 & \\
\hline $3-19$ & 53.3 & -9.9 & & & & & 0.857 & 1.884 & & 0. & & & \\
\hline $3-20$ & 53. & -7. & 66 & 4 & & & 0.858 & 1.886 & & & & & \\
\hline $3-20$ & 53.3 & -12.7 & 66.9 & 40 & & & 0.858 & 1.887 & 0.5 & & & 6 & \\
\hline $3-20$ & 53.3 & -15.0 & 66.9 & $40 .($ & 95 & & 0.858 & 1.886 & 0.6 & 1.0 & & 3 & \\
\hline $3-20$ & 53.3 & -18.9 & 67.0 & & & 7. & 0.858 & 1.887 & 0.76 & e. & .17 & 2 & \\
\hline $3-21$ & 53.3 & -26.1 & 66.8 & 4 & 997 & 7.3 & 0.858 & 1.886 & 1.0 & 2. & & 7 & \\
\hline & 26.7 & -19.6 & 86. & & & & 0.859 & 1.896 & & & & & \\
\hline & 26.7 & & & & & & 0.858 & 876 & & & & & \\
\hline & 26. & & & & & & 0.858 & 1.860 & & & & & \\
\hline & 26. & -10 & 87. & & & & 0.859 & 1.907 & 0.4 & & & 3 & \\
\hline $3-2$ & 26.7 & -7 & 88. & 3.3 & 065 & 2. & 0.858 & 1.900 & & & 12 & 0 & \\
\hline $3-23$ & 35.6 & -7 & & 3.1 & 930 & 4.0 & 0.859 & 1.901 & 0.28 & 0. & 0.63 & 35 & 45 \\
\hline $3-2$ & 35.6 & -7 & 77. & & & 3. & 0.858 & 1.871 & ) 2 & & & 2 & \\
\hline & 35. & -10 & & & & & 0.859 & 1.880 & & & & & \\
\hline & 35.6 & -10.2 & & & & & 0.859 & 1.912 & & & & & \\
\hline & & & & & & & 0.859 & 871 & & & & & \\
\hline & & & & & & & 0.859 & 1.8 & & & & & \\
\hline & 35. & & & & & & 0.859 & 1.879 & & & & 3 & \\
\hline $3-2$ & 35. & -1 & & & 52 & & 0.859 & 1.899 & & 1.07 & & .581 & 76 \\
\hline $3-23$ & 35.6 & -15 & & 2 & 098 & 3. & 0.859 & 1.888 & 0.60 & 1 & & 3 & \\
\hline $3-23-01 / 10$ & 35. & -19 & & 2 & 959 & 3. & 0.859 & 1.876 & 7 & 8 & & 54 & \\
\hline $3-23-01 / 11$ & 35.6 & -19.0 & & 29.4 & 108 & 3.8 & 0.859 & 1.894 & 0.759 & 1.30 & 36 & 709 & .742 \\
\hline & 35.6 & & & & & 3.8 & 0.859 & 1.903 & 1.000 & 1.67 & & 910 & 0.901 \\
\hline & 26.7 & & & & & 1. & 0.862 & 2.091 & & & & & \\
\hline & 26. & & & & & $2 .($ & 0.863 & 2.119 & & & & & \\
\hline & & & & & & 2. & 0.863 & 2.184 & & . & & & \\
\hline & 26. & & 114 & & & 2.1 & 0.863 & 2.161 & & 0. & 0.82 & .558 & 0.521 \\
\hline & 53. & & & & & 10.8 & 0.841 & 2.439 & 0.77 & 27 & 2.39 & .795 & 0.691 \\
\hline $10-11-02 / 9$ & 53.3 & -19 & & & 129 & 10.8 & 0.841 & 2.439 & 4 & 2.69 & 2.87 & 0.777 & 0.829 \\
\hline $10-12-02 / 7$ & 53.3 & -20.4 & & 40.1 & 1.131 & 10.8 & 0.840 & 2.437 & 0.864 & 2.77 & 2.91 & 0.802 & 0.844 \\
\hline $10-12-02 / 8$ & 53.3 & -21.7 & 51.4 & & 1.131 & 10.8 & 0.841 & 2.437 & 0.914 & 3.05 & 3.17 & 0.883 & 0.918 \\
\hline $10-12-02 / 11$ & 53.3 & -25.0 & 50.7 & 40.2 & 1.141 & 10.8 & 0.841 & 2.429 & 1.000 & 3.52 & 3.68 & 1.021 & 1.070 \\
\hline
\end{tabular}

* $n_{a}$ Calculated Using $\mathrm{Nu}$ from equation (16)

Rime shapes $\left(n_{a}=1.0\right)$ reproduce the collectionefficiency curve around the airfoil because all water impinging at a given location will freeze there. Typical rime shapes used in this study are given in figures 2 (c). The relatively smooth leading edge with a well-defined maximum makes it easy to establish the ice thickness from a table of the ice coordinates. The two tracings compared in the figure had ice thicknesses that differed by only $2.8 \%$.

Rime tests can be used to help validate tunnel $L W C$ calibrations. The temperature used for the test of figure 2 (c) was calculated as the maximum for which fully 


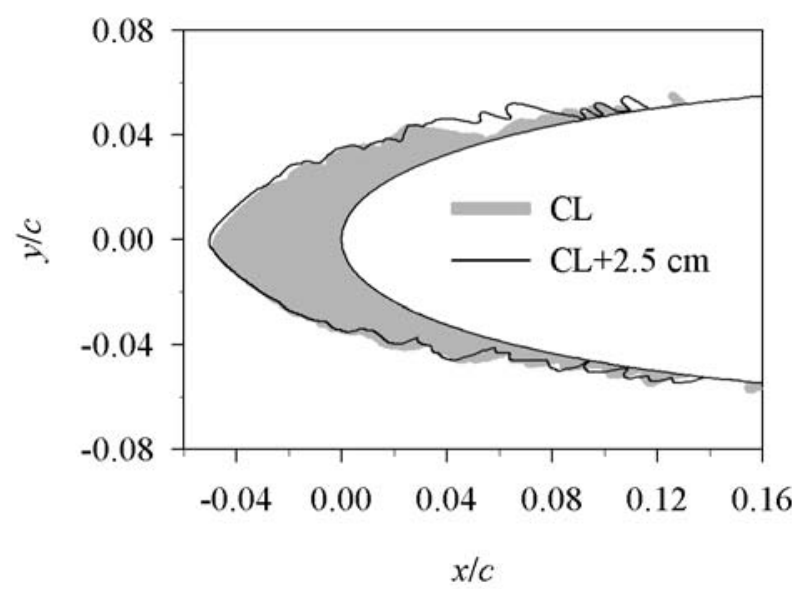

(c) Ice Shapes from 3-21-01 Run 4. Rime Ice with $n_{a}=$ 1.00 .

Figure 2. concluded.

rime ice would form for the specified model size, and test conditions. If the true $L W C$ had been significantly higher than indicated from the calibration, evidence of glaze ice at the leading edge would have been seen. On the other hand, if the true $L W C$ was lower than the calibrated value fully rime accretions would be seen for higher temperatures. Thus, for a given set of test conditions, if there is confidence in the temperature, velocity and droplet $M V D$, a series of tests in which the temperature is incrementally increased in small steps above the calculated maximum value for rime should either validate or identify problems with the $L W C$ calibration.

For temperatures higher than the maximum temperature for rime, $n_{a}$ will be less than unity. Therefore, glaze features should occur at the leading edge for there to be consistency between the analytical freezing fraction and experimental ice shapes. Results of tests with temperatures incremented above the maximum for rime will be presented later.

Comparison of Analytical and Experimental Freezing Fraction

The experimentally-derived freezing fractions are plotted against the Messinger analytical values in figure 3 . Open symbols were measured from the ice tracings at mid-span (CL) and the solid from the tracings $2.5 \mathrm{~cm}$ above mid-span $(\mathrm{CL}+2.5 \mathrm{~cm})$. The solid line represents perfect agreement of the two freezing fractions and the shaded band indicates the limits for $\pm 10 \%$ agreement. A linear fit to the data is also shown as a dashed line.

As noted above, there can be significant uncertainty in the ice thickness values found from tracings at low freezing fractions. The data scatter in figure 3 at the lowest freezing fraction tested was a consequence of this uncertainty. The linear fit to the data fell within the

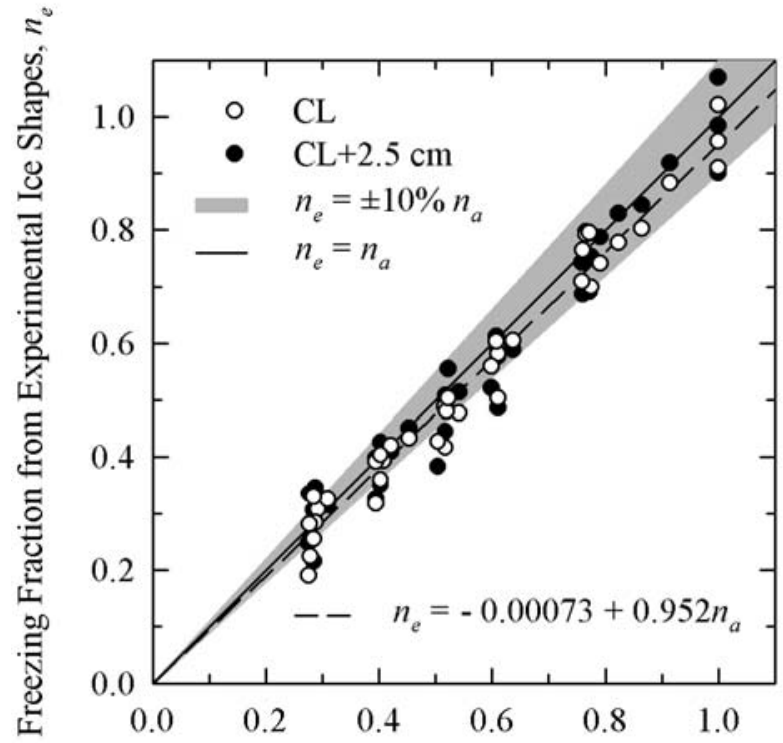

Freezing Fraction from Analysis, $n_{a}$

Figure 3. Experimental and Analytical Freezing Fractions Compared. $n_{a}$ calculated with length $d$ using equation (16) for $\mathrm{Nu}$.

$\pm 10 \%$ agreement band, although on average $n_{e}$ values tended to about $5 \%$ lower than the $n_{a}$. The value of $n_{e}$ found from equation (1) is inversely proportional to the value of $L W C$ through the accumulation parameter (eq. (2)). Because the accuracy for the $L W C$ is estimated to be about $\pm 12 \%$, this agreement is as good as can be expected.

While $n_{a}=1$ suggests fully rime ice, $n_{e}$ is susceptible to the uncertainties in both the $L W C$ calibration and the tracing technique and can therefore be greater or less than unity. $n_{e}$ values for experimental rime shapes in this study were within $\pm 10 \%$ of 1 .

Unlike the results of reference 5, the experimentallydetermined freezing fractions for this study showed no systematic deviation from the analytical values at low freezing fractions. This consistently good agreement between $n_{e}$ and $n_{a}$ over a range of conditions including both fully rime and fairly warm glaze argues against the contention that the Messinger freezing fraction formulation neglects any important surface-water effects.

\section{Ice Shapes for Freezing Fractions Near 1}

For the conditions of 10-12-02, run 11, a static temperature of $-25^{\circ} \mathrm{C}$ was the maximum that would produce an analytical freezing fraction of 1 . Four additional tests were made with temperatures of -22 to $-18^{\circ} \mathrm{C}$ with corresponding $n_{a}$ of 0.91 to 0.78 to determine the effect of freezing fraction on ice shape for conditions not quite fully rime. The results are shown in figure 4. The shape for fully rime ice is shaded in each portion of the 
figure and the near-rime shape is given as a solid line for comparison. The rime shape conformed approximately to the leading-edge contour of the model, as seen previously for somewhat different rime conditions in figure 2 (c).

When the analytical freezing fraction was reduced from 1 to 0.91 (fig. 4 (a)), a narrow strip of ice at the leading edge changed from the characteristic white appearance of rime to a slightly transparent form. At the same time the smooth, convex shape of typical rime within this narrow strip was replaced with a slight valley that can be seen in the figure. The remainder of the ice aft of

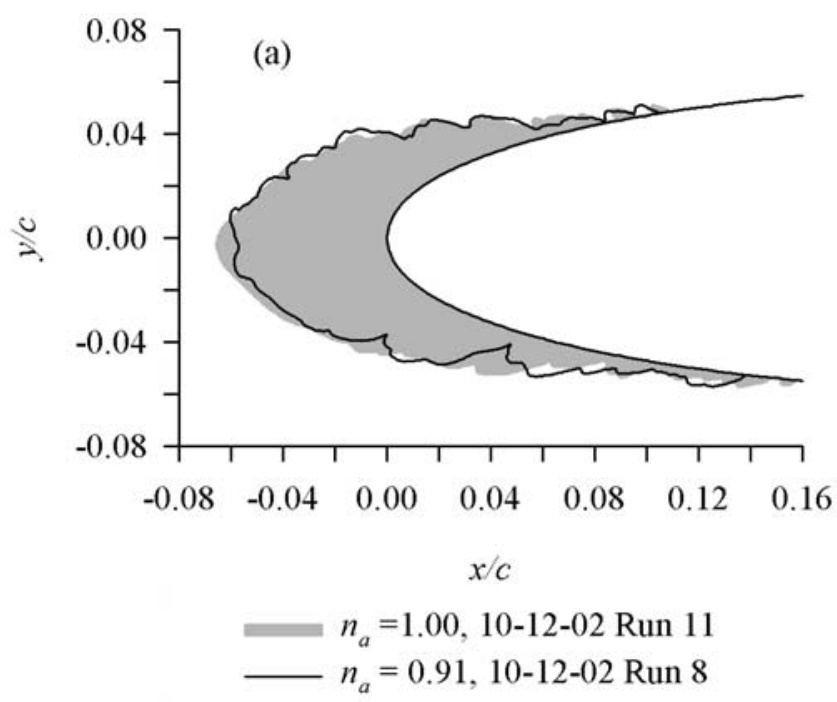

(a) Freezing Fraction of 0.91 Compared with Fully Rime

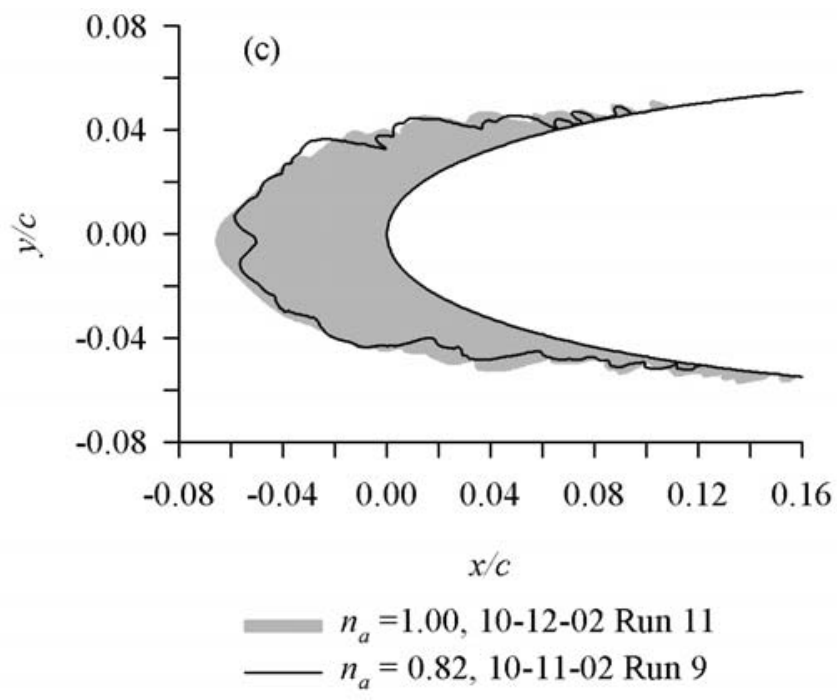

(c) Freezing Fraction of 0.82 Compared with Fully Rime this narrow strip at the leading edge maintained the rime appearance. Further reductions in freezing fraction to 0.87 (fig. 4 (b)), 0.83 (fig. 4 (c)) and 0.78 (fig. 4 (d)) caused the leading-edge depression to deepen slightly without changing the rime appearance aft of the leading edge.

These results show that the use of the Messinger analysis leads to a calculated freezing fraction of 1 when ice shapes are indeed fully rime and less than 1 when glaze features begin to show at the leading edge. Thus, the results of figures 3 and 4 together show that freezing fractions calculated according to equations (3) - (17)

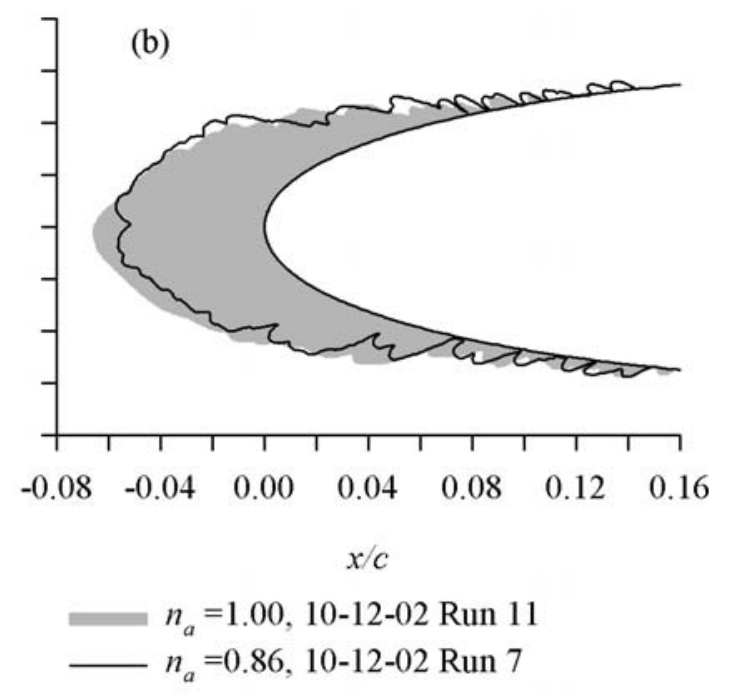

(b) Freezing Fractions of 0.86 Compared with Fully Rime

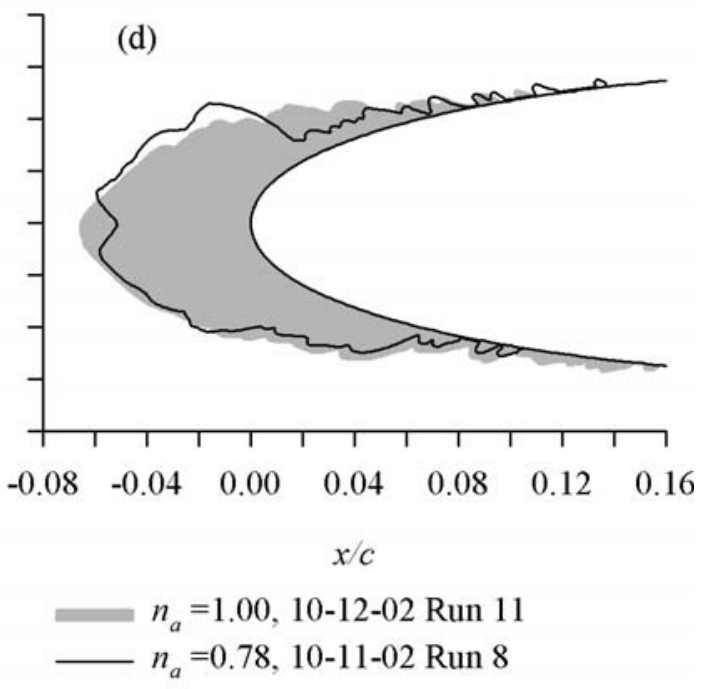

(d) Freezing Fractions of 0.78 Compared with Fully Rime

Figure 4. Effect of Freezing Fraction on Ice Shape at and near $n=1$. See Table I for Test Conditions. 
satisfy both tests (i) and (ii) of the Introduction.

Effect of Modifications to the Freezing Fraction Calcu$\underline{\text { lations }}$

Next the effect of modifying the freezing fraction calculations will be shown. First, the comparison of experimental and analytical freezing fractions will be repeated with model chord substituted for $d$ in equations (1), (2), (15) and (17). Note that the same value of $n_{e}$ is obtained from equation (1) whether $c$ or $d$ is used because both non-dimensional ice thickness and $A_{c}$ are inversely proportional to model size. Figure 5 (a) gives the results of this exercise. The $n_{a}$ based on $c$ were lower than those using $d$. Consequently, the mean $n_{e}$ was just over $10 \%$ higher than $n_{a}$. The differences between $n_{e}$ and $n_{a}$ might still be explained by the $L W C$ calibration uncertainty, so the general trend of the $n_{e} v s n_{a}$ comparison does not indicate a problem. However for all three of the rime cases in Table I, replacing $d$ with $c$ resulted in $n_{a}$ decreasing to a value significantly below unity even though the experimental shapes obtained were fully rime. For example, $n_{a}$ for the conditions of figure 2(c), went from 1 to 0.82 and the rime reference conditions for fig. 4 now produced $n_{a}=0.89$. Therefore, the value of $n_{a}$ used in figure 5 cannot be correct if the $L W C$ calibration is reasonably accurate.

Figure 5 (b) shows another example of the effect of modifying the freezing fraction calculation, this time using $d$ but calculating heat transfer from

$$
N u=0.0239 R e^{0.805}
$$

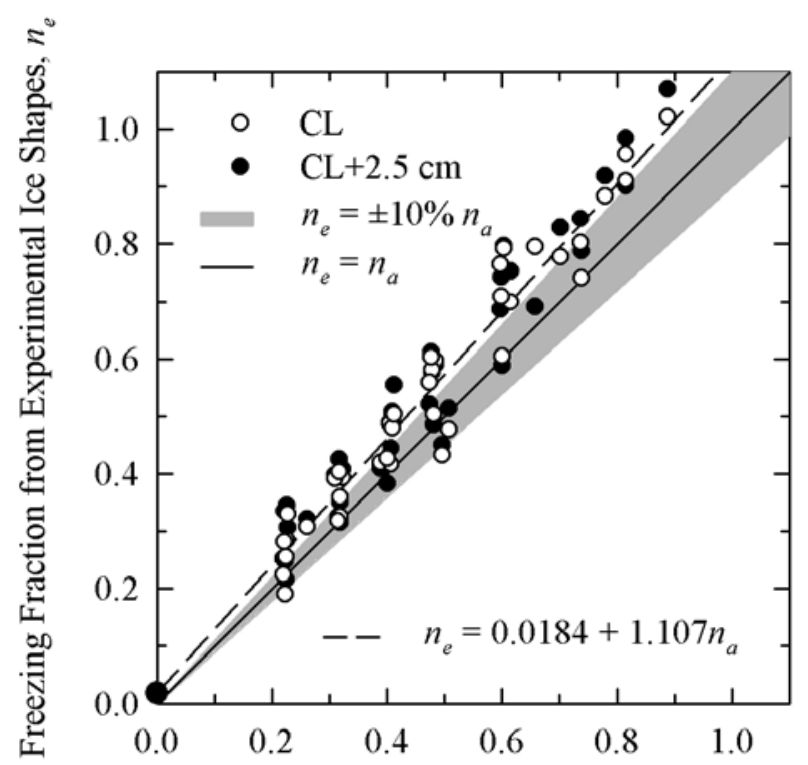

Freezing Fraction from Analysis, $n_{a}$

(a) $n_{a}$ calculated with length $c$.

Figure 5. Effect of Simple Modifications to Freezing Fraction Calculations instead of equation (16). Equation (21) was quoted by Kreith $^{8}$ from results published by Hilpert ${ }^{13}$ for the average $N u$ around a single cylinder in cross flow at $R e$ in the range 40,000 to 400,000 . For the present study $R e$ varied from 55,000 to 120,000 , so it might not seem unreasonable to use equation (21) to determine $n_{a}$.

Again, the values of $n_{e}$ were in reasonable agreement with this new value of $n_{a}$ as seen in figure $5(\mathrm{~b})$. However, once again when test conditions produced rime shapes, this analysis produced freezing fractions below 1. For example, the conditions of figure 2 (c) gave $n_{a}=$ 0.89 and those of the rime reference shape for figure 4 resulted in $n_{a}=0.84$. Thus, both the analyses used for figures 5a) and (b) failed test (ii) of the Introduction.

The low value of $n_{a}$ at rime could be an indication of the inaccuracy of the tunnel $L W C$ calibration. Suppose, for example, that the true tunnel $L W C$ for the tests of Table I was $20 \%$ lower than the values reported there and used in the calculation of $n_{a}$. Repeating the analysis of figure 5 (b) with all $L W C$ 's reduced to $80 \%$ of the values in Table I, the values of $n_{a}$ increased about $15 \%$ such that rime conditions were now represented by an analytical freezing fraction of 1 or nearly 1 . However, at the same time the $n_{e}$ were increased by about $25 \%$, resulting in a much poorer comparison between the two freezing fractions, as can be seen in figure 5 (c). Furthermore, $n_{e}$ values for the conditions that produced rime shapes became roughly $15-20 \%$ greater than 1 . This inconsistency between $n_{a}$ and $n_{e}$ indicates that the problems seen in figure 5 (b) are more fundamental

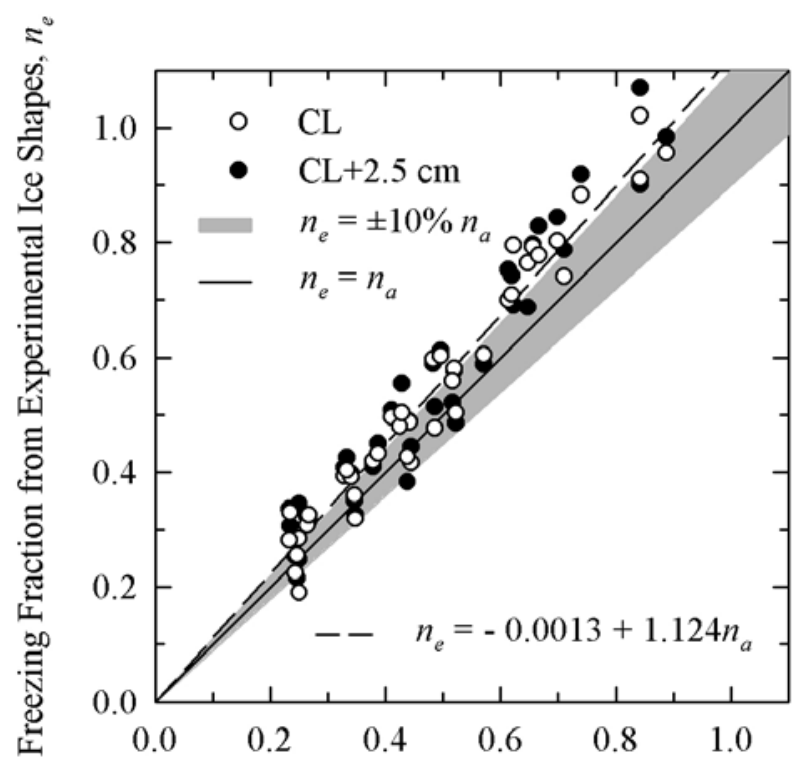

Freezing Fraction from Analysis, $n_{a}$

(b) $n_{a}$ calculated using equation (21) with length $d$.

Figure 5. (con't). 


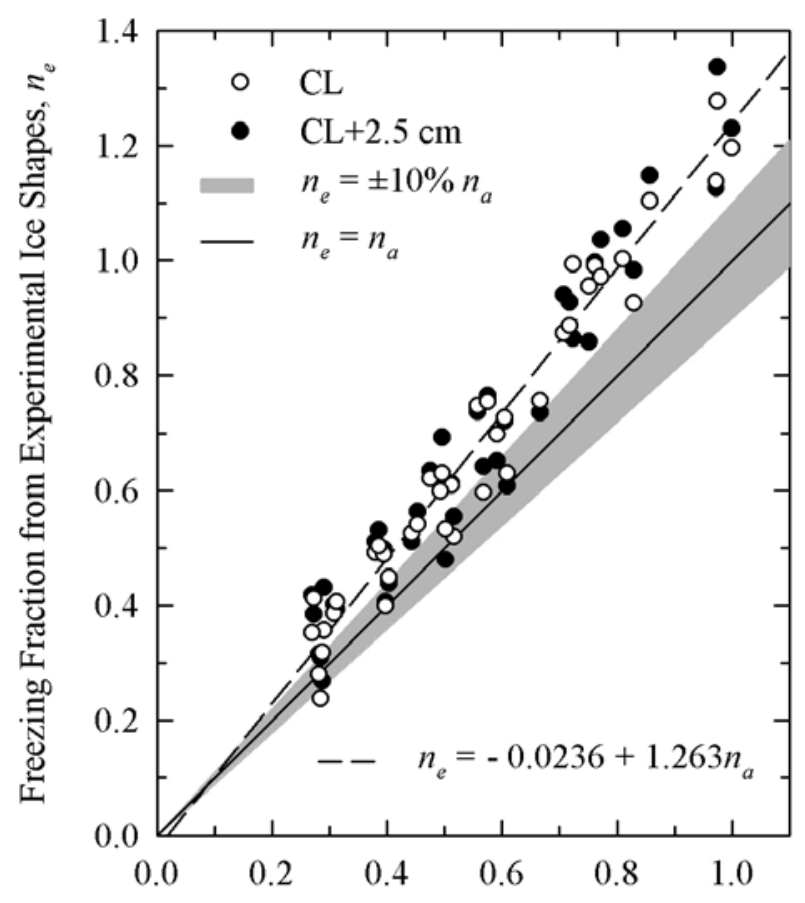

Freezing Fraction from Analysis, $n_{a}$

(c) $n_{a}$ calculated with $N u$ used for figure 5 (b), but assuming actual $L W C 20 \%$ lower than calibration.

Figure 5. (concluded)

than a problem with the $L W C$ calibration.

\section{Concluding Remarks}

Figure 3 illustrated that the two tests of the Introduction are satisfied by the Messinger analysis as represented by equations (3) - (17). (i) There was generally good agreement between the ice-thickness freezing fractions and the analytical values and (ii) the Messinger analysis led to freezing fractions of 1 for conditions that produced rime shapes. Within the ability to measure experimental ice shapes, there was no indication that the Messinger analysis overlooks any significant physical processes affecting the freezing fraction.

The results in figure 5 show how leading-edge thickness measurements and the $n_{e}$ derived from them can be used to check both the soundness of the freezing fraction analysis and infer the reliability of the tunnel $L W C$ calibration.

These observations may not be valid for very short icing sprays. For such situations, convection and conduction heat transfer to and along the model surface may need to be included in the analytical expression for freezing fraction. Some analysis is needed to estimate how far into the icing spray such terms might be significant.
For scaling studies, scale and reference values of freezing fraction are matched to establish scale temperature or $L W C$. As long as the same analytical expressions are used for both reference and scale, some variation in the freezing fraction analysis is possible with little effect on the calculated scale conditions. For applications such as ice-accretion prediction codes, it is more important to insure the correct analytical expressions.

At freezing fractions of 0.3 and less, variations in recorded leading-edge thickness from one span-wise location to another of as much as $30 \%$ were observed. At higher freezing fractions the variations were typically less than $8 \%$. Much of the difference noted in ice thickness was an indication of the error inherent in manual tracing of ice. To some extent, the random nature of ice accretion is also revealed by these tracings. Currently used tracing methods need to be improved for better analysis, although these methods are adequate for routine ice-shape comparisons and scaling studies.

For this work, the Messinger analysis for freezing fraction as described by Ruff was applied using twice the leading-edge airfoil radius as the relevant length for the various parameters. Results using chord produced analytical freezing fractions as low as 0.82 for conditions that gave fully rime ice shapes. This inconsistency suggested that the use of chord for the relevant length is not correct.

A convective heat-transfer film coefficient represented by $N u \propto R e^{0.5}$ was used in the analysis. Analytical freezing fractions determined using an alternate form, $N u \propto R e^{0.8}$, also resulted in freezing fractions of less than 1 at rime conditions.

For the Appendix-C conditions at which this study was performed, the IRT $L W C$ calibration was consistent with experimental ice shapes and freezing fractions.

\section{$\underline{\text { References }}$}

${ }^{1}$ Messinger, B.L., "Equilibrium Temperature of an Unheated Icing Surface as a Function of Airspeed," $J$. Aeron. Sci. vol. 20 no. 1, January 1953, pp 29-42.

${ }^{2}$ Ruff, G.A., "Analysis and Verification of the Icing Scaling Equations," AEDC-TR-85-30, vol 1 (Rev), March 1986.

3 Anderson, David N., “Acceptable Tolerances for Matching Icing Similarity Parameters in Scaling Applications," AIAA-2001-0832, January 2001.

${ }^{4}$ Langmuir, Irving and Blodgett, Katharine B.: "A Mathematical Investigation of Water Droplet Trajectories," Army Air Forces Technical Report No. 5418, February 1946. 
${ }^{5}$ Bilanin, A.J., "Proposed Modifications to the Ice Accretion/Icing Scaling Theory," AIAA Paper AIAA-88-0203, January 1988.

${ }^{6}$ Tribus, Myron, Young, G.B.W. and Boelter, L.M.K., "Analysis of Heat Transfer Over a Small Cylinder in Icing Conditions on Mount Washington," Trans. ASME vol. 70, November 1948, pp 971-976.

${ }^{7}$ Charpin, Francois and Fasso, Guy, "Essais de givrage dans la grande soufflerie de Modane sur maquettes a echelle grandeur et echelle reduite," L'Aeronautique et l'Astronautique, no. 38, 1972, pp 23 - 31. English translation published as "Icing Testing in the Large Modane Wind-Tunnel on Full-Scale and Reduced Scale Models," NASA TM-75373, March 1979.

${ }^{8}$ Kreith, Frank, Principles of Heat Transfer, International Textbook Co., Scranton, 1958.
9 Poinsatte, Philip E., "Heat Transfer Measurements from a NACA 0012 Airfoil in Flight and in the NASA Lewis Icing Research Tunnel," NASA CR 4278, March 1990.

${ }^{10}$ Ide, Robert F. and Oldenburg, John R., "Icing Cloud Calibration of the NASA Glenn Icing Research Tunnel," AIAA-2001-0234, January 2001.

11 Anderson, David N., "A Preliminary Study of IceAccretion Scaling for SLD Conditions," AIAA-20020521, January 2002.

12 Anderson, David N., and Feo, Alejandro "IceAccretion Scaling Using Water-Film Thickness Parameters," AIAA-2002-0522, January 2002.

13 Hilpert, R., "Wärmeabgabe von geheizten Drähten und Rohren," Forsch. Gebiete Ingenieurw., vol. 4, 1933, p 215. 


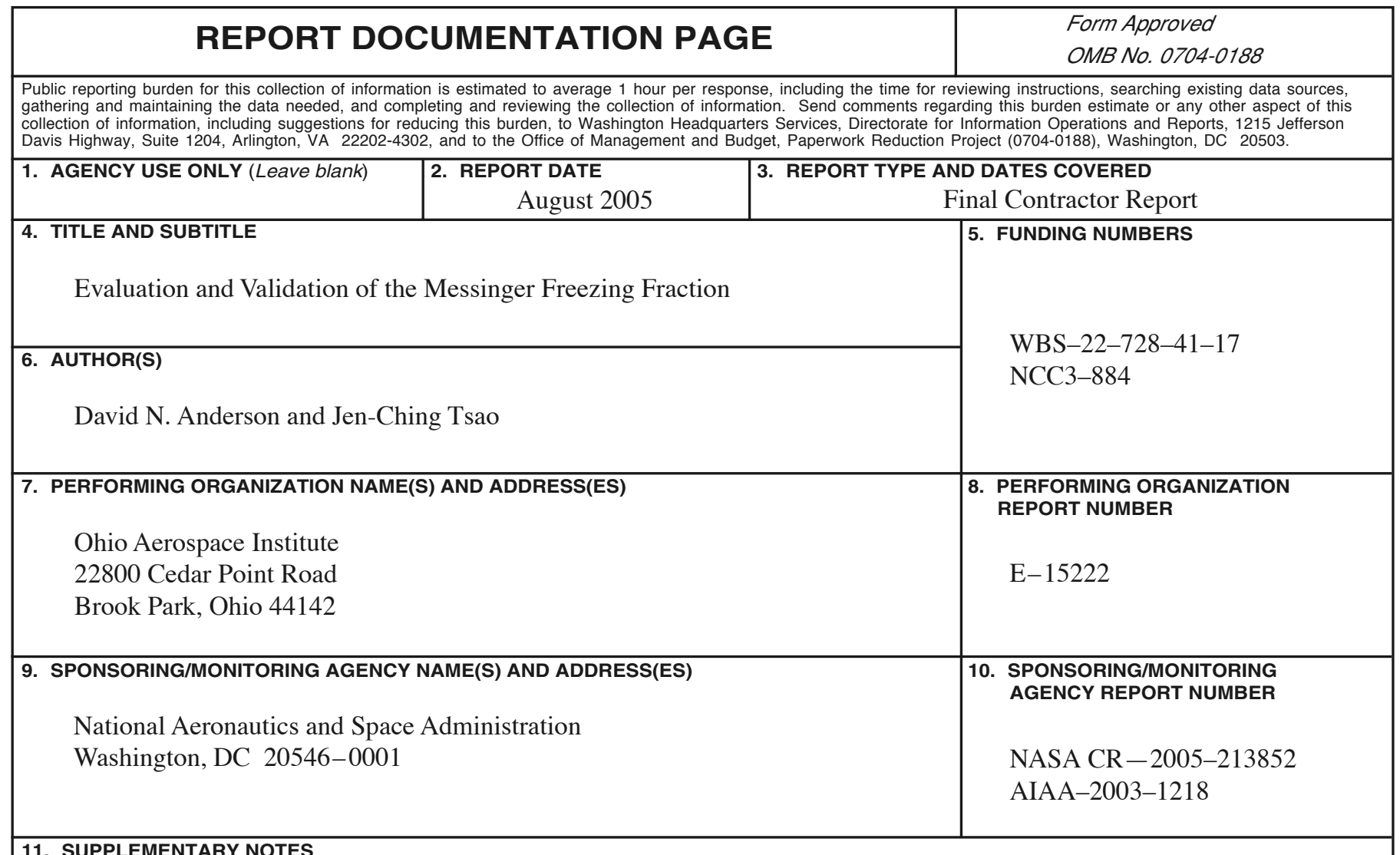

11. SUPPLEMENTARY NOTES

Prepared for the 41st Aerospace Sciences Meeting and Exhibit sponsored by the American Institute of Aeronautics and Astronautics, Reno, Nevada, January 6-9, 2003. Project Manager, Thomas H. Bond, Instrumentation and Controls Division, NASA Glenn Research Center, organization code RI, 216-433-3900.

12a. DISTRIBUTION/AVAILABILITY STATEMENT 12b. DISTRIBUTION CODE

Unclassified - Unlimited

Subject Category: 03

Available electronically at http://gltrs.grc.nasa.gov

This publication is available from the NASA Center for AeroSpace Information, 301-621-0390.

13. ABSTRACT (Maximum 200 words)

One of the most important non-dimensional parameters used in ice-accretion modeling and scaling studies is the freezing fraction defined by the heat-balance analysis of Messinger. For fifty years this parameter has been used to indicate how rapidly freezing takes place when super-cooled water strikes a solid body. The value ranges from 0 (no freezing) to 1 (water freezes immediately on impact), and the magnitude has been shown to play a major role in determining the physical appearance of the accreted ice. Because of its importance to ice shape, this parameter and the physics underlying the expressions used to calculate it have been questioned from time to time. Until now, there has been no strong evidence either validating or casting doubt on the current expressions. This paper presents experimental measurements of the leading-edge thickness of a number of ice shapes for a variety of test conditions with nominal freezing fractions from 0.3 to 1.0 . From these thickness measurements, experimental freezing fractions were calculated and compared with values found from the Messinger analysis as applied by Ruff. Within the experimental uncertainty of measuring the leading-edge thickness, agreement of the experimental and analytical freezing fraction was very good. It is also shown that values of analytical freezing fraction were entirely consistent with observed ice shapes at and near rime conditions: At an analytical freezing fraction of unity, experimental ice shapes displayed the classic rime shape, while for conditions producing analytical freezing fractions slightly lower than unity, glaze features started to appear.

\begin{tabular}{|c|c|c|c|}
\hline \multicolumn{3}{|l|}{ 14. SUBJECT TERMS } & $\begin{array}{c}\text { 15. NUMBER OF PAGES } \\
17 \\
\end{array}$ \\
\hline NSN 7540-01-280-5500 & & & $\begin{array}{l}\text { andard Form } 298 \text { (Rev. 2-89) } \\
\text { scribed by ANSI Std. Z39-18 } \\
-102\end{array}$ \\
\hline
\end{tabular}



